\title{
Persisten las preguntas* Factores ambientales en las enfermedades autoinmunes
}

T ras el nacimiento de su primera hija, comenzaron a aparecer moretones en el cuerpo de Stanley Finger. Despertado súbitamente la mayoría de las noches por el llanto de su bebé, Finger, semidormido, tropezaba al dirigirse hacia la habitación de aquél, golpeándose contra las paredes y los muebles en la oscuridad. "Mi esposa y yo bromeábamos al respecto", dice Finger, ingeniero químico de Bluffton, Carolina del Sur. Sin embargo, durante un chequeo rutinario, Finger se enteró de que la causa de la facilidad con la que le salían moretones era que el número de sus plaquetas estaba disminuyendo drásticamente. El cuerpo depende de estos fragmentos celulares para la coagulación, y la cuenta de plaquetas de Finger había bajado a casi un tercio de su valor normal. Después de descartar el cáncer y otras enfermedades, el doctor de Finger llegó finalmente a un diagnóstico: púrpura trombocitopénica inmune (PTI).

La PTI es una enfermedad autoinmune, un padecimiento que se presenta cuando el sistema inmune ataca a las células y los tejidos del cuerpo. Cuando se le diagnosticó a Finger en 1974, aún no se percibían las enfermedades autoinmunes como amenazas a la salud pú- blica, como se las ve hoy en día. Sin embargo, según Fred Miller, director del Grupo de Autoinmunidad Ambiental del Instituto Nacional de Ciencias de Salud Ambiental, actualmente se reconoce que las enfermedades autoinmunes se cuentan entre las principales causas de muerte entre las mujeres jóvenes y de mediana edad de los Estados Unidos. Es más: los índices de prevalencia para algunas de estas enfermedades se están incrementando debido a causas que Miller considera en gran parte ambientales:"Nuestras secuencias genéticas no están cambiando con la suficiente rapidez como para ser la causa de estos incrementos", dice Miller. "Pero nuestro medio ambiente sí:tenemos 80000 sustancias químicas cuyo uso está aprobado en el comercio, pero sobre cuyos efectos sobre el sistema inmune sabemos muy poco. Nuestros estilos de vida también son diferentes de como eran hace apenas unas cuantas décadas, y comemos más alimentos procesados." Si bien los índices de prevalencia de las enfermedades del corazón y del cáncer continúan reduciéndose, dice Miller, las enfermedades autoinmunes podrían convertirse en algunos de los padecimientos más costosos y más onerosos en los Estados Unidos.

* Publicado originalmente en Environmental Health Perspectives, volumen 119, número 6, junio 2011, páginas A248-A253. 


\section{Una familia de enfermedades se extiende}

Hasta hace poco, los científicos no consideraban las enfermedades autoinmunes como un grupo de padecimientos relacionados entre sí, sino que veían cada una de las enfermedades como independiente de las demás y, generalmente, como una aflicción poco común. La PTI, por ejemplo, aqueja apenas a 10 personas de cada $100000^{1}$ (en comparación, la Organización Nacional de Trastornos Poco Comunes define las enfermedades poco comunes como aquellas que aquejan cuando mucho a 250 personas por cada 100000 ). Dado que nadie había aglutinado las enfermedades autoinmunes en un mismo grupo, se desconocía su impacto acumulativo sobre la salud y la sociedad.

Esto preocupó a Noel Rose, inmunólogo y profesor de la Universidad Johns Hopkins, quien estaba convencido de que la ciencia médica no estaba poniendo suficiente atención a aquello que las enfermedades autoinmunes tienen en común. De modo que a mediados de la década de los 1990 Rose comenzó a hacer lo que nadie más había hecho: junto con un pequeño grupo de colegas rebuscó en los artículos publicados en revistas y otras fuentes epidemiológicas en un intento de calcular cuántas personas se veían aquejadas por cada uno de 24 padecimientos autoinmunes, incluyendo esclerosis múltiple, artritis reumatoide (AR), lupus eritematoso sistémico (LES) y diabetes mellitus tipo 1. Utilizando proyecciones de población para el año 1996 de la Oficina del Censo de EUA, Rose llegó finalmente al cálculo de que estos padecimientos, considerados conjuntamente, aquejaban a 1 de cada 3 estadounidenses: más de 8.5 millones de personas en aquel entonces. ${ }^{2}$ "Eso resultó asombroso", dice Rose. "Hasta entonces nadie se había dado cuenta de que las enfermedades autoinmunes abundan tanto."
Según cálculos actuales de los Institutos Nacionales de Salud, hasta 23.5 millones de estadounidenses pueden estar aquejados de al menos un padecimiento autoinmune. ${ }^{3}$ Pero Rose señala que ese número no hace referencia a los datos del Censo de EU del año 2010; es más, proviene de la evaluación de Rose de dichas 24 enfermedades inmunes, según la cual el número real de estas enfermedades oscila entre 80 y $120 .{ }^{4}$ El tamaño real de la población afectada en Estados Unidos podría llegar a ser de 50 millones de personas, ${ }^{5}$ según la Asociación Americana de Enfermedades Autoinmunes (en inglés, AARDA), un grupo de apoyo con sede en el este de Detroit.

Las enfermedades autoinmunes tienden a agruparse entre los miembros de una familia. Sin embargo, aunque un par de gemelos idénticos tengan la misma susceptibilidad genética a heredar enfermedades, Rose dice que es posible que sólo uno de ellos desarrolle un padecimiento autoinmune, lo que sugiere la intervención de disparadores ambientales.

Los científicos definen esos disparadores de manera amplia: se han citado sustancias químicas, agentes infecciosos, estrés, hormonas, fármacos, drogas, alimentación, aumento de peso, comportamientos, etc., como factores etiológicos. Rose reconoció que el incremento podría deberse en parte a los cambios en el diagnóstico. "Es difícil descartar esa posibilidad porque ahora la conciencia clínica de estas enfermedades es mucho mayor que antes", dice. "Pero también hay estudios muy buenos que muestran incrementos reales, en particular de la diabetes tipo 1."6,7 El hecho de que la diabetes tipo 1 ha estado bien caracterizada durante décadas constituye hasta el momento una evidencia convincente de que el incremento en la incidencia no es una mera ilusión basada en un mejor diagnóstico.

Jill Norris, profesora de epidemiología de la Escuela de Salud
Pública de Colorado, añade que la prevalencia de la enfermedad celiaca-padecimiento autoinmune del intestino delgado provocado por la exposición al gluten, una proteína que se encuentra en el trigo, la cebada y el centeno- también parece estarse incrementando drásticamente en Estados Unidos. " "Probablemente estamos viendo una mezcla de diferentes tendencias", dice Norris. Si bien algunas enfermedades autoinmunes van en aumento, otras están disminuyendo: por ejemplo la prevalencia de la AR parece estar reduciéndose en la población, señala. "Y en cuanto a la mayoría de las demás", añade", "no sabemos, sobre todo porque no tenemos registros adecuados para rastrearlas."

\section{La complejidad de las enfermedades autoinmunes, revelada}

Los científicos dividen las enfermedades autoinmunes en dos categorías generales: las variedades específicas de un órgano (como la diabetes tipo 1 , que es un ataque inmune a las células productoras de insulina del páncreas) y las variedades sistémicas (como el LES, que se presenta cuando el sistema inmune se vuelca contra múltiples órganos y tejidos del cuerpo). Los resultados clínicos varían según la enfermedad y van desde los trastornos hemorrágicos en la PTI a la incapacidad de procesar la glucosa en la diabetes tipo 1 y hasta el dolor y la inflamación de las articulaciones en la AR.

Dado que las enfermedades autoinmunes suelen ser poco comunes y con frecuencia no son fáciles de diagnosticar mediante exámenes de sangre, imágenes y otras pruebas estándar, a los médicos clínicos que no están familiarizados con estas enfermedades pueden resultarles desconcertantes. No es raro que los médicos descarten a pacientes verdaderamente enfermos calificán- 


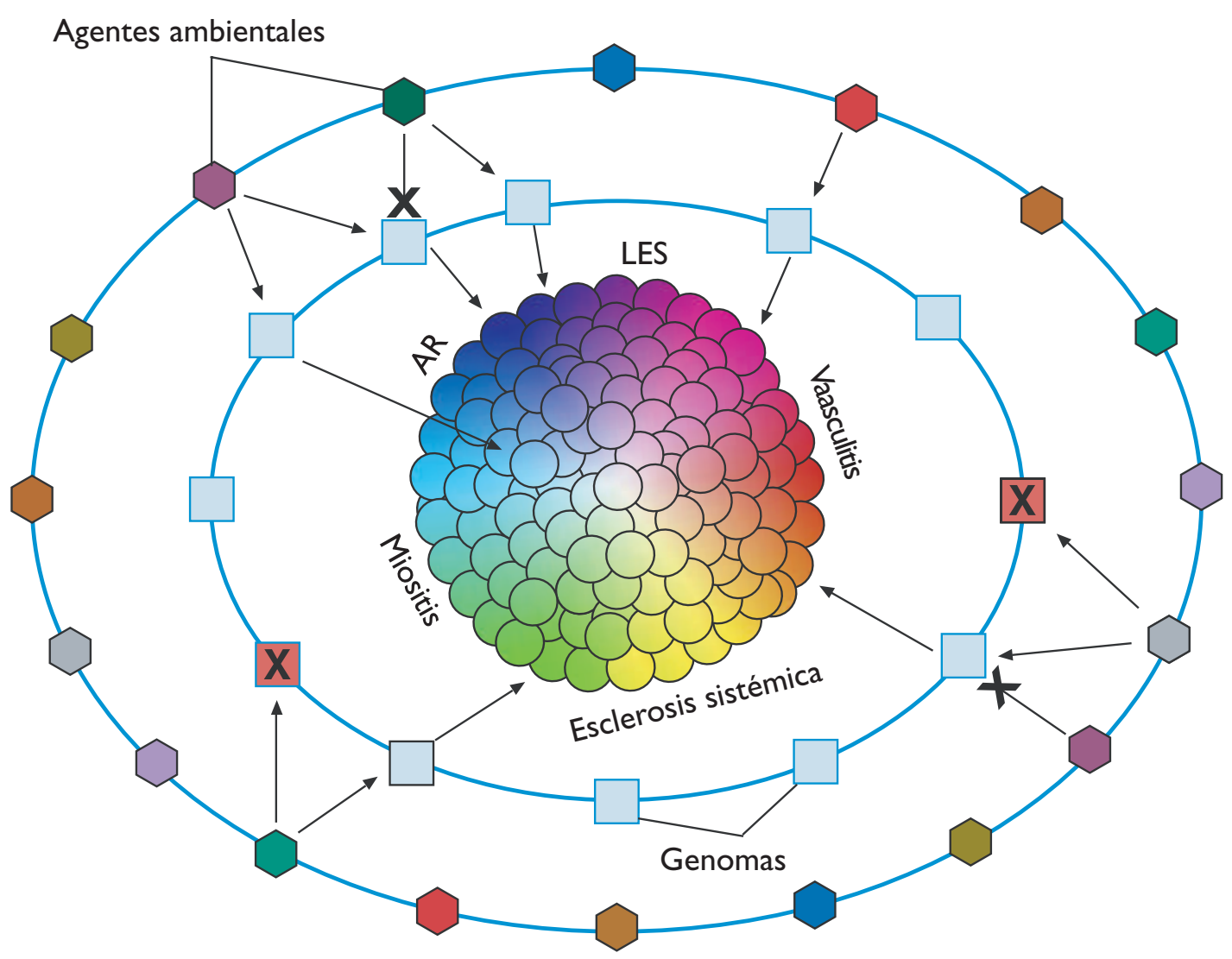

\section{Interacciones entre los genes y el medio ambiente y las enfermedades autoinmunes: una hipótesis}

\footnotetext{
egún la hipótesis del trastorno elemental, las enfermedades autoinmunes se consideran como conjuntos integrados por muchos fenotipos individuales, cada uno de los cuales está definide por un conjunte único de síntomas, signes y hallazgos de laboratorio. Fsta nigura utiliza el ejemplo de las enfermedades reumáticas sistémicas, un subconjunto de enfermedades inmunes, para conceptualizar cómo pueden producirse diversos fenotipos de enfermedades a consecuencia de distintas interacciones entre los genes y el medie ambiente.

Cada esfera representa un fenotipo de enfermedad; cada cuadro representa el genoma de un individue, y cada hexágone representa una exposición ambiental particular Según esta hipótesis, algunas combinaciones de genomas y exposiciones ambientales dan lugar a deter minados fenotipos de enfermedad, mientras que otras combinaciones pueden no producirlos. En otros casos, un factor ambiental $\odot$ un genoma, indicad॰ acú con una $\mathrm{X}$, puede brindar protección contra el desarrollo de una enfermedad.
}

\section{$A \mathbf{R}=$ artritis reumatoide; 1 ES = lupus eritematoso sistémico.}

Fuente: Gourley M, Miller FW. Mechanisms of disease: environmental factors in the pathogenesis of rheumatic disease. Nat Clin Pract Rheumatol 2007;3(3):I72-180; dois I 0. I038/ncprheum0435 (Reimpreso con autorización). 
dolos de perezosos o neuróticos, dice Finger, actual presidente del consejo directivo de la AARDA. "Pueden requerirse años para diagnosticar algunos de estos padecimientos". "Los pacientes pueden ser referidos de un especialista a otro. Incluso apenas en el año 2000 los profesionales de la salud mental eran los primeros en realizar un diagnóstico correcto."

Todas las enfermedades autoinmunes se presentan cuando el sistema inmune del cuerpo se vuelve contra sí mismo. Pero según Kathleen Gilbert, inmunóloga y profesora de la Universidad de Ciencias Médicas de Arkansas, eso es prácticamente lo único que sabemos con certeza acerca de ellas. Los científicos, dice, apenas han arañado la superficie en lo tocante a saber qué es lo que provoca una enfermedad autoinmune.

Este campo está repleto de teorías y mecanismos biológicos en conflicto y carece de un concepto unificador, añade K. Michael Pollard, profesor adjunto del Instituto Scripps de Investigación. "Por cada inmunólogo hay una o dos teorías sobre las causas de las enfermedades autoinmunes", dice. "Ese es el estado en el que se encuentra este campo: hemos realizado un gran número de buenos trabajos, pero hay tantos tipos de enfermedades, que todas ellas presentan diferencias en su mecánica que pueden ser sutiles o profundas."

En algunos casos las enfermedades autoinmunes ocurren cuando unas proteínas anormales llamadas auto-anticuerpos atacan a células y tejidos en lugar de a los invasores extraños como los virus y las bacterias. Eso es lo que ocurre en la enfermedad de Graves: los auto-anticuerpos se ligan a los receptores de hormonas en la glándula tiroidea. Como resultado, el órgano se sobreactiva, lo que da lugar a síntomas entre los que se incluyen la intolerancia al calor, una pérdida de peso inexplicada, ojos saltones, hipertensión y temblor. O bien, las células $\mathrm{T}$ pueden atacar a células y tejidos, dice Gilbert, como ocurre cuando destruyen las células de islote que producen la insulina en el páncreas, dando lugar a la diabetes tipo 1.

Pero incluso las enfermedades causadas por linfocitos $\mathrm{T}$ pueden verse acompañadas por una proliferación de auto-anticuerpos que es posible detectar antes de que se manifiesten los síntomas. Por ejemplo, los médicos pueden evaluar la condición del sistema autoinmune en los niños que se cree puedan estar en riesgo de contraer diabetes tipo 1, midiendo los niveles en la sangre de auto-anticuerpos contra la insulina y otros antígenos.

Rose añade que algunas enfermedades autoinmunes comparten componentes heredables, como las variaciones en el gen que codifica el antígeno leucocitario humano (en inglés, HLA). El HLA es la versión humana de una importante familia de genes llamada complejo mayor de histocompatibilidad (en inglés, MHC), que desempeña un papel crucial en la inmunidad de los vertebrados. Una variedad en particular de MHC conocida como el haplotipo HLA-A1-B8-DR3, dice, interviene en varias enfermedades autoinmunes. De hecho, la mayoría de las enfermedades autoinmunes pueden estar ligadas a variaciones del HLA de uno u otro tipo, añade. "De modo que esto me dice que son fundamentales para la etiología de las enfermedades autoinmunes", concluye Rose.

No obstante, Rose reconoce que si bien muchas variaciones de genes están ligadas a las enfermedades autoinmunes, cada una de ellas aporta sólo un porcentaje pequeño del riesgo total. La enfermedad ocurre sólo cuando múltiples genes actúan juntos, dice, y aun en ese caso la genética no alcanza a explicar por completo el riesgo, lo que indica que entran en juego factores ambientales. "Sin embargo, tenemos muy poca información sobre estos factores", añade Rose. "Necesitamos más datos que asocien las enfermedades inmunes con exposiciones específicas. También necesitamos mecanismos biológicos verosímiles que expliquen cómo es que esas exposiciones provocan o exacerban las enfermedades. En esto se enfocará nuestra principal labor de investigación en la próxima década."

\section{Vínculos ambientales}

Según Pollard, hasta ahora la mejor evidencia sobre la relación entre las exposiciones ambientales y las enfermedades autoinmunes es la que procede de estudios de fármacos. Esto no es de extrañar, dice, puesto que los pacientes de esos estudios son controlados cuidadosamente por lo que respecta a la dosis, el resultado clínico y la confusión derivada de otros factores. Pollar señala que en una minoría de pacientes se han vinculado de manera concluyente al LES dos fármacos en particular: la procainamida, un tratamiento para la arritmia cardiaca, y la hidralazina, utilizada para tratar la presión arterial alta. " $Y$ cuando se les retira el fármaco a los pacientes, sus síntomas de lupus desaparecen", dice Pollard.

Además de la relación entre estas exposiciones farmacéuticas y el LES, también hay evidencias sólidas que vinculan la ingestión de gluten con la enfermedad celiaca; de hecho, los síntomas desaparecen cuando se elimina de su dieta el gluten, según Alessio Fasano, director del Centro de Investigación Celiaca de la Escuela de Medicina de la Universidad de Maryland. Sin embargo, la evidencia humana de otros vínculos entre el medio ambiente y estas enfermedades es más tenue, debido en parte 


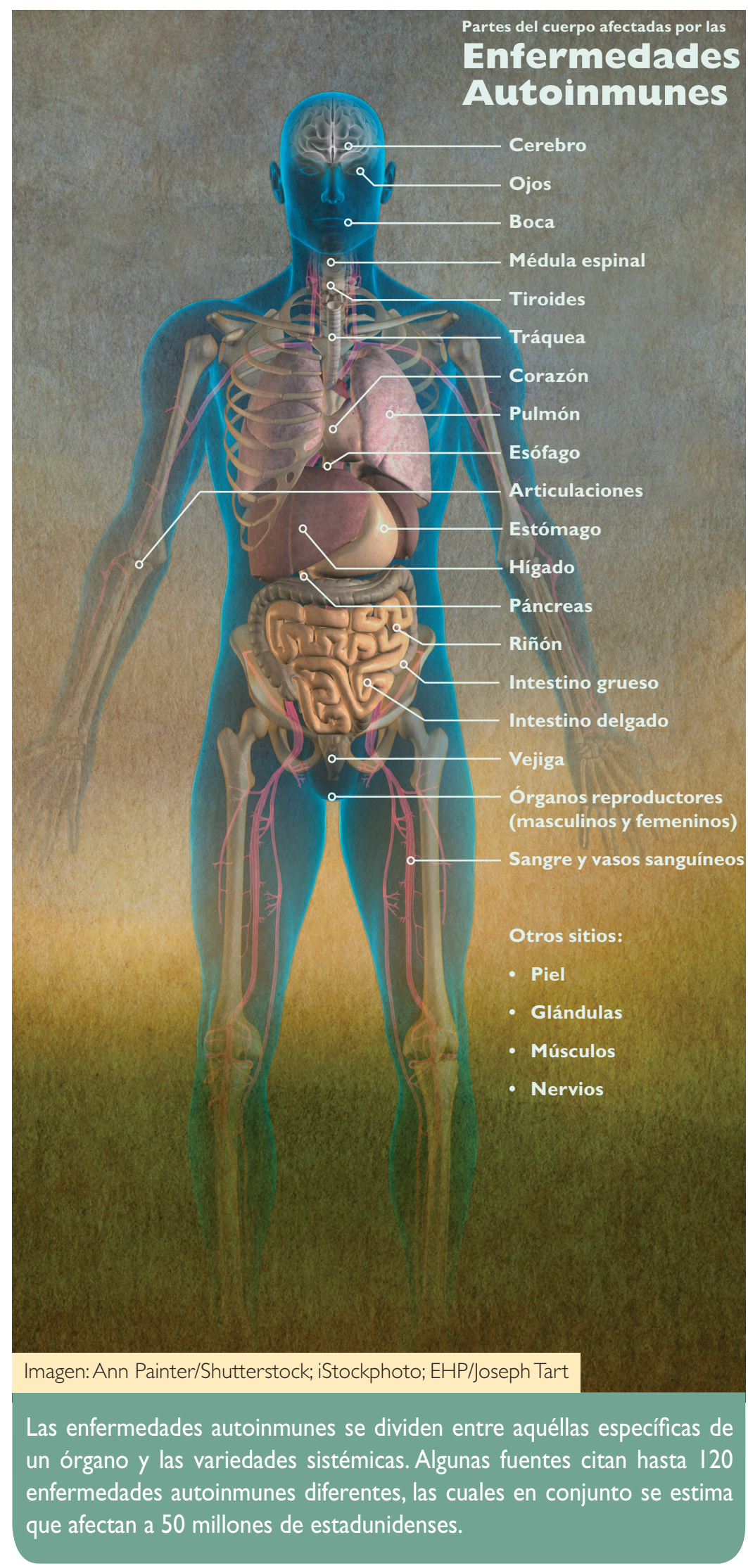

a las limitaciones inherentes de la epidemiología ambiental, afirma Pollard: las personas tienden a la movilidad y están expuestas a múltiples agentes ambientales a la vez, y con frecuencia los síntomas de las enfermedades autoinmunes tardan un tiempo considerable en comenzar a manifestarse.

Por otra parte, los vínculos propuestos también tienden a verse afectados por resultados contradictorios de los estudios. Por ejemplo, estudios realizados en el Reino Unido, Suecia y Japón relacionaron el tabaquismo con el LES, ${ }^{10,11,12}$ pero en tres estudios realizados en Estados Unidos no se encontró una conexión similar. $13,14,15$

Las fuentes entrevistadas para este artículo coincidieron unánimemente en que el incremento de los índices de prevalencia es más evidente en el caso de la diabetes tipo 1. Datos obtenidos del sistema nacional de salud de Finlandia demuestran que los índices de diabetes tipo 1 se incrementaron a más del doble, pasando de 31 casos por cada 100,000 personas en 1980 a 64 casos por cada 100,000 personas en el año 2005. ${ }^{16}$ También se detectaron incrementos en otros 17 países europeos, en un porcentaje anual de $3.9 \%$ de 1989 a $2003 .{ }^{17}$ Los autores de dicho estudio predijeron que el número de casos nuevos en niños menores de 5 años en Europa se duplicaría para 2020 respecto a 2005, mientras que el número de casos en los niños menores de 15 años se incrementará en $70 \% .{ }^{17}$

Norris señala que también se han documentado incrementos de diabetes tipo 1 en Estados Unidos por medio de un programa de detección de diabetes en los jóvenes llamado SEARCH, coordinado por los Centros para el Control y Prevención de Enfermedades de EU.18 El programa SEARCH rastrea los datos de incidencia recopilados en los registros de seis estados: Colorado, California, Hawaii, Ohio, Carolina 
del Sur y Washington. Norris dice que en Colorado el número de casos se incrementó de 15 por cada 100,000 personas en el periodo de 1978-1988 a 23.9 por cada 100,000 personas entre 2002 y 2004. "Ese es un incremento de alrededor de $70 \%$ ", agrega. "No es tan grande como en que se ve en Finlandia, pero sí es sustancial."

\section{La diabetes: un ejemplo que viene al caso}

¿Qué es lo que está ocasionando el incremento de la diabetes tipo 1 ? Terence Wilkin, profesor de endocrinología y metabolismo de la Escuela de Medicina Península en Plymouth, $\mathrm{RU}$, cita incrementos constantes en el peso de los niños a edades cada vez menores. Según Wilkin, una masa corporal más pesada exacerba la resistencia a la insulina, o el proceso mediante el cual la insulina pierde la capacidad de coordinar el metabolismo de la glucosa. Eso pone a las células pancreáticas beta en marcha directa: en la lucha por satisfacer las demandas de insulina, las células beta se agotan, lo que provoca el desencadenamiento de la enfermedad. "Vemos de manera sistemática que los niños con mayor peso desarrollan diabetes más tempranamente", dice Wilkin. "Y el vínculo con la resistencia a la insulina explica por qué está sucediendo esto."

Norris dice que la hipótesis de Wilkin tiene sentido a un nivel intuitivo. Pero al citar datos prospectivos ${ }^{19}$ del Estudio de Autoinmunidad en la Diabetes en los Jóvenes (en inglés, DAISY), coordinado por la Universidad de Colorado en Denver, Norris afirma que algunos niños presentan evidencias de autoinmunidad (medida según el número de anticuerpos dirigidos contra las células de islotes pancreáticos en la sangre) antes de mostrar señales de tener mayor peso o estatura de lo normal. "Según nuestros datos no hay ninguna asociación entre el peso corporal y el índice de masa corporal y el futuro surgimiento de una enfermedad autoinmune", explica. "Podría ser que el incremento de peso y la resistencia a la insulina sean posteriores al inicio de la enfermedad autoinmune", añade. "De modo que yo no descartaría por completo la teoría de Wilkin: simplemente quizá tengamos que ajustarla a los datos."

Es más, la cohorte del estudio DAISY está limitada a niños en riesgo identificados por tipo de HLA, agrega Norris, mientras que la hipótesis de Wilkin puede ser aplicable a poblaciones infantiles más amplias que no se limiten a individuos genéticamente susceptibles. "Y no hemos probado la hipótesis de Wilkin en la población general", concluye Norris.

Mientras tanto, algunos investigadores han propuesto que la diabetes tipo 1 podría estar relacionada con el consumo de las fórmulas infantiles, mismo que se popularizó después de la Segunda Guerra Mundial. Estudios retrospectivos realizados sobre todo en Finlandia y otros países llevaron esta visión un paso más allá al mostrar asociaciones con el consumo de leche de vaca específicamente..$^{20}$ Sin embargo, las investigaciones prospectivas más recientes, ${ }^{21,22,23,24}$ que al decir de Norris no están aquejadas por los problemas de sesgo de recuerdo que caracterizan en ocasiones a los diseños retrospectivos, no han podido confirmar estas asociaciones. En cambio, estos estudios han vinculado la diabetes tipo 1 a otras exposiciones alimentarias en los bebés y niños pequeños, incluyendo cereales con y sin gluten, tubérculos y frutas.

"No estoy segura de que podamos decir que un factor por sí solo en la alimentación de los bebés sea el más importante", dice Norris. "Hay demasiada variabilidad en lo que nos muestran los estudios; podría no tratarse de un solo factor." Agrega que los datos también sugieren que la diabetes tipo 1 puede estar relacionada con los enterovirus ${ }^{25}$ y con los contaminantes, incluyendo la presencia de nitratos y nitrosaminas derivadas de los nitratos en el agua utilizada para beber. ${ }^{26}$

\section{Pistas sobre los mecanismos de autoinmunidad}

Son principalmente los estudios ocupacionales, en los que las exposiciones pueden determinarse con mayor confiabilidad con base en la memoria y los registros de los lugares de trabajo que en los estudios de la población general, los que vinculan los compuestos industriales y sustancias químicas con las enfermedades autoinmunes. Algunas de las asociaciones que más apoyan dichos estudios, señala Miller, vinculan la exposición ocupacional a la sílice cristalina con enfermedades tales como AR, LES y esclerosis sistémica (conocida también como esclerodermia), una enfermedad de los tejidos conectivos. ${ }^{27,28,29}$

Jean Pfau, profesora adjunta de inmunotoxicología de la Universidad del Estado de Idaho, sugiere que la sílice y el asbesto -el cual ha sido asociado con AR, LES y escleroderma en los mineros y otros residentes del pueblo de Libby, Montana, ${ }^{30}$ anteriormente dedicado a la explotación de minas de asbesto- evocan las enfermedades autoinmunes de maneras similares. Ambos compuestos se incrustan en los pulmones, dice, lo que sirve para atraer a las células inmunes y producir inflamación. Es más, la sílice y el asbesto son citotóxicos, de modo que matan a las células en formas que pueden generar mucho detritus celular. Pfau señala que posiblemente las células B del área inflamada "pierdan tolerancia" al material del propio organismo, es decir, al detritus celular, y procedan a producir auto-anticuerpos 
correspondientes a ese detritus que ataquen a las células sanas en todo el cuerpo. Se podrían desencadenar procesos similares debido a la exposición viral, agrega, poniendo como ejemplo la exposición al virus de Epstein-Barr que ha sido causa de AR y LES. ${ }^{31}$

Igualmente importante en la literatura sobre inmunotoxicología es el solvente tricloroetileno (TCE), un contaminante de las aguas subterráneas sumamente generalizado. En un estudio realizado por Gilbert y sus colegas se encontró que la exposición al TCE alteraba la expresión de las células $\mathrm{T}$ auxiliares en los ratones, volviéndolos menos susceptibles a la apoptosis (muerte celular programada). ${ }^{32}$ "Se supone que la apoptosis evita que las células T auxiliares autorreactivas -o más específicamente, el subconjunto de células $\mathrm{CD} 4^{+} \mathrm{T}$ que expresan la proteína CD4 en sus superficies- se expandan y provoquen enfermedades autoinmunes", explica Gilbert. "De modo que la supresión de este proceso puede incrementar la vulnerabilidad a una variedad de enfermedades."

Los ratones de Gilbert expuestos al TCE presentaron evidencias de actividad inmune en el hígado, incluyendo alteraciones de las citoquinas y cambios en la expresión de de genes en linfocitos con dosis no tóxicas. ${ }^{32} \mathrm{~A}$ la larga, los ratones desarrollaron hepatitis autoinmune, dice, pero los efectos del TCE sobre las células $\mathrm{CD} 4^{+} \mathrm{T}$ no necesariamente se limitan a las enfermedades hepáticas.

Mientras tanto, varios estudios también asocian los solventes, incluyendo el TCE; , con enfermedades autoinmunes como la AR, el LES y la esclerosis sistémica. ${ }^{27}$ Es difícil decir si esas asociaciones son reales o no, añade Gilbert, porque los seres humanos están típicamente expuestos a mezclas de sustancias químicas.
Pollard señala que los estudios bien controlados en seres humanos son un eslabón perdido en la investigación sobre las enfermedades autoinmunes. "Estas enfermedades son poco comunes, de modo que se requieren estudios grandes para detectar las asociaciones, y eso cuesta mucho dinero", dice. "Tenemos fragmentos y piezas sueltas: por ejemplo, existen varios reportes de personas expuestas en minas que tienen algunas características de las enfermedades autoinmunes, pero esas personas también están expuestas a muchas otras sustancias. En eso consiste el mayor problema: necesitamos datos duros sobre poblaciones que están y que no están expuestas, y no es fácil realizar esos estudios."

\section{Necesidades para el futuro}

Lo que más se necesita, dice Miller, son mejores datos que documenten la frecuencia y ubicación de las enfermedades autoinmunes en la población. "Estamos hablando de un registro nacional, algo que nos permita tomar control de los focos de las enfermedades en relación con determinadas exposiciones ambientales", añade. "Eso nos permitiría ver de qué maneras cambian esas enfermedades con el paso del tiempo."

Miller señala el programa de Vigilancia, Epidemiología y Resultados Finales (en inglés, SEER) ${ }^{33}$ del Instituto Nacional de Cáncer como un ejemplo de un registro exitoso. El programa SEER recopila información sobre la incidencia, prevalencia y supervivencia de cáncer en zonas que representan $28 \%$ de la población de Estados Unidos, así como datos para todo el país. "No tenemos nada como eso para las enfermedades autoinmunes", dice Miller. Como consecuencia, añade, mientras que se suele abordar los cánceres como una sola entidad, cada una de las enfermedades autoinmunes es vista aisladamente, lo cual impide un uso más eficaz de los fondos destinados a la investigación.

Según Rose, la obtención de mejores diagnósticos también constituye una importante prioridad. Hoy en día, dice, a la mayoría de las personas aquejadas de enfermedades inmunes no se les diagnostican éstas hasta que el proceso de la enfermedad ya está demasiado avanzado. "Tenemos evidencias fidedignas de que esas enfermedades pueden desarrollarse durante años antes de manifestarse clínicamente", dice Rose. "Para cuando vemos a estos pacientes, ya ha habido mucho daño, y nos vemos ante la difícil tarea de tratar de arreglar esto. Sería mejor dar con ellos antes, por lo que es absolutamente necesario encontrar mejores bioindicadores que ayuden a predecir quiénes están en riesgo."

\section{Mtro. Charles W. Schmidt \\ Escritor científico galardonado \\ de Portland, ME, ha publicado en Discover Magazine, Science, y Nature Medicine.}

\section{Referencias}

I. Segal JB, Powe NR. Prevalence of immune thrombocytopenia: analyses of administrative data. J Thrombo Haemost 2006;4(I I):2377-2383; doi: 10.1 I I I/j. I538-7836.2006.02147.x

2. Jacobson DL, et al. Epidemiology and estimated population burden of selected autoimmune diseases in the United States. Clin Immunol Immunopathol 1997;84(3):223-243; doi: 10.1006/ clin. 1997.4412

3. The Autoimmune Diseases Coordinating Committee. Progress in autoimmune disease research. Informe al Congreso. Publicación del NIH N $05-5 \mid 40$. Bethesda, MD:The Autoimmune Diseases Coordinating Committee, National Institute of Allergy and Infectious Diseases, National Institutes of Health, 2005 [consultado abril 27, 20I I]. Disponible en: http:// tinyurl.com/3wev5xh 
4.AARDA. The cost burden of autoimmune disease:The latest front in the war on healthcare spending. Eastpointe, Ml:American Autoimmune Related Diseases Association, Inc., 20I I [consultado abril 27, 20I I]. Disponible en: http:// tinyurl.com/4yucztc

5.AARDA. Questions \& answers. How many americans have an autoimmune disease? [website]. Eastpointe, Ml:American Autoimmune Related Diseases Association, Inc. [consultado abril 27, 20I I]. Disponible en: http://tinyurl. com/44exjhg

6. Podar T, et al. Increasing incidence of childhood-onset type I diabetes in 3 Baltic countries and Finland 1983-1998. Diabetologia 200I;44(suppl 3):BI7-B20; PMID:I I7244I0 7. Grimaldi LME, et al. High prevalence and fast rising incidence of multiple sclerosis in Caltanissetta, Sicily, Southern Italy. Neuroepidemiology 2007;28(I):28-32; doi:10.1 I59/000097853

8. Rubio-Tapia A, et al. Increased prevalence and mortality in undiagnosed celiac disease. Gastroenterology 2009; I37(I):88-93; doi:10.1053/j.gastro.2009.03.059 9. Pollard KM, et al.Toxicology of autoimmune diseases. Chem Res Toxicol 2010;23(3):455-466; doi: $10.1021 / t \times 9003787$

10. Nagata C, et al. Systemic lupus erythematosus: a case-control epidemiologic study in Japan. Int J Dermatol 1995;34(5):333-337; PMID:7607794

I I. Hardy CJ, et al. Smoking history, alcohol consumption, and systemic lupus erythematosus: a case-control study.Ann Rheum Dis 1998;57:45 I-455; doi: I0. I I36/ard.57.8.45 | 12. Bengtsson AA, et al. Risk factors for developing systemic lupus erythematosus: a case-control study in southern Sweden. Rheumatology 2002;4I(5):563-57I; doi:10.1093/ rheumatology/4I.5.563

13. Weetman AP. Determinants of autoimmune thyroid disease. Nature Immunol 200 I;2(9):769770; doi:10.1038/ni0901-769

14. Vestergaard P, et al. Smoking as a risk factor for Graves' disease, toxic nodular goiter, and autoimmune hypothyroidism. Thyroid 2002; 12(I):69-75; doi:10.1089//0507250275345/995

15. Reidenberg MM, et al.Acetylation phenotypes and environmental chemical exposure of people with idiopathic systemic lupus erythematosus.

Arthritis Rheum 1993;36(7):971-973;

doi: I0.1002/art. 17803607|4

16. Harjutsalo V, et al.Time trends in the incidence of type I diabetes in Finnish children: a cohort study. Lancet 2008;37I(9626): I777- I782; doi:I0.10I6/SOI40-6736(08)60765-5

17. Patterson CC, et al. Incidence trends for childhood type I diabetes in Europe during 1989-2003 and predicted new cases 2005-20: a multicentre prospective registration study. Lancet 2009;373(9680):2027-2033; doi:10.1016/S0 I406736(09)60568-7

I8. SEARCH for Diabetes in Youth Study [website].Atlanta, GA: US Centers for Disease Control and Prevention; Bethesda, MD:National Institute of Diabetes and Digestive and Kidney Diseases, 2010 [consultado abril 28, 20I I].

Disponible en: http://tinyurl.com/3fvtkfp

19. Lamb MM, et al. Height growth velocity, islet autoimmunity, and type I diabetes development: the Diabetes Autoimmunity Study in the Young. Diabetologia 2009;52(10):2064-207I; doi: 10.1007/s00 I25-009-1428-2

20. Knip M, et al. Infant feeding and the risk of type I diabetes. Am J Clin Nutr 20 10;9I(5):I506S-15।3S; doi: 10.3945/ ajcn.20I0.2870IC

2I. Ziegler A-G, et al. Early infant feeding and risk of developing type I diabetes-associated autoantibodies. JAMA 2003;290(I3): I72I-1728; doi:10.1001/jama.290.13.1721

22.Virtanen SM, et al.Age at introduction of new foods and advanced beta cell autoimmunity in young children with HLA-conferred susceptibility to type I diabetes. Diabetologia 2006;49:15 I2 |52I; doi: I0.1007/s00 |25-006-0236-I

23. Norris JM, et al.Timing of initial cereal exposure in infancy and risk of islet autoimmunity. JAMA 2003;290(I3): I7|3-1720; doi:10.1001/jama.290.13.1713
24. Couper J], et al. Lack of association between duration of breast-feeding or introduction of cow's milk and development of islet autoimmunity. Diabetes 1999;48(I I):2 I 45-2 149; doi:10.2337/diabetes.48.11.2145

25. Yeung WC, et al. Enterovirus infection and type I diabetes mellitus: systematic review and meta-analysis of observational molecular studies. BM] 20 I I;342:d35; doi: 10.1 I36/bmj.d35 [en línea el 3 de febrero de 201 I].

26. Longnecker MP, Daniels JL. Environ Health Perspect 200I;109(suppl 6):87I-876; PMID:I 7744505

27. Gourley M, Miller FW. Mechanisms of disease: environmental factors in the pathogenesis of rheumatic disease. Nat Clin Practice Rheumatol 2007;3(3): I72-180; doi:10.1038/ncprheum0435

28. Calvert GM, et al. Occupational silica exposure and risk of various diseases: an analysis using death certificates from 27 states of the United States. Occup Environ Med 2003;60(2):I22-129; doi:I0.II36/oem.60.2. 122 29. Stolt $P$, et al. Quantification of the influence of cigarette smoking on rheumatoid arthritis: results from a population based case-control study, using incident cases. Ann Rheum Dis 2003;62(9):835-84I; doi: 10.I I36/ard.62.9.835

30. Noonan CW, et al. Nested case-control study of autoimmune disease in an asbestosexposed population. Environ Health Perspect 2006; I I4(8): I 243- I 247; doi: I0. I289/ehp.9203

3I. Costenbader KH, Karlson EW. Epstein-Barr virus and rheumatoid arthritis: is there a link? Arthritis Res Ther 2006;8(I):204-210; doi: I0.1 I86/ar 1893

32. Gilbert KM, et al. Environmental contaminant trichloroethylene promotes autoimmune disease and inhibits T-cell apoptosis in $\mathrm{MRL}^{+/+}$ mice.J Immunotoxicol 2006;3(4):263-267; PMID: 18958707

33. Surveillance Epidemiology and End Results (SEER) Program [website]. Bethesda, MD:National Cancer Institute, National Institutes of Health [consultado abril 28, 20I I]. Disponible en: http://tinyurl.com/5s6k5gq 